ISSN: 1641-4713; e-ISSN: 2081-1160

DOI: https://doi.org/10.36551/2081-1160.2021.27.1-6

\title{
A razão deste dossiê
}

The reason for this dossier

\author{
Maria Luiza Tucci Carneiro \\ LEER-USP (www.usp.br/leer) \\ Universidade de São Paulo, Brasil \\ E-mail:malutucci@gmail.com
}

O dossiê temático trata especificamente da história, dos espaços e da memória dos grupos de (i)migrantes distintos por suas comunidades de origem que, a partir do século XIX, optaram pelo Brasil como país de destino ou por São Paulo, como a metrópole das oportunidades. Quanto aos protagonistas destes cenários, temos os artistas de origem europeia atuantes no eixo Rio/São Paulo, principalmente as criadas europeias, sobretudo de cor, radicadas no Rio de Janeiro; os imigrantes portugueses das Ilhas dos Açores fixados na Colônia Agrícola de Vianna, na então Capitania do Espírito Santo; os descendentes de italianos no Brasil, e os nordestinos radicados em São Paulo.

Do ponto de vista das diferentes formas de escrever a História do Brasil, desde o século XIX aos dias atuais, o dossiê também nos instiga a repensar o momento atual da história do mundo abalado pelos fluxos constantes de refugiados e imigrantes ilegais. Tais imbricações nos remetem ao mundo do trabalho, das guerras, das transformações das relações sociais e políticas que interferem na formação do imaginário coletivo e na reabilitação das identidades, das culturas e da memória coletiva. Muitas vezes, os desencantos com a pátria de origem, os encantos e os estranhamentos com o país de destino, reafirmam os sentimentos de pertencimento e/ou aceleram o processo de desenraizamento social. Daí a importância de reconstituirmos tais mutações através das narrativas e representações produzidas por (i)migrantes, a partir do entrelaçamento dos conceitos de identidade, exclusão e globalização. 
A partir de alguns exemplos pontuais, o dossiê pretende lançar um olhar crítico e elaborado sobre a realidade do fenômeno migratório que, neste século XXI, afirma-se com características múltiplas herdadas do nosso passado. Do ponto de vista histórico, tal proposta permite avaliar um conjunto de ciclos migratórios que, desde o século XIX, têm provocado rearranjos na ordem mundial, tendo em vista o volume de indivíduos em trânsito no atual mundo globalizado. E o Brasil, como tantos outros países da América Latina, tem sido alvo destes deslocamentos de pessoas que, ameaçadas nas suas comunidades de origem, estão em busca de um espaço e do reconhecimento dos seus direitos.

Neste século XXI, tais fluxos - sob o impacto da visibilidade proporcionada pelas redes sociais - têm exposto as novas fontes de conflitos no mundo provocadas por guerras civis, terrorismo, genocídios em curso e outros tantos fenômenos que implicam em expulsão forçada, massacres, estupros de mulheres, prostituição, apropriação de bens e territórios. Tais situações de anomalia, expõem também as fraturas (históricas, sociais e políticas) que afetam a vida de milhões de indivíduos, nem sempre protegidos por organizações governamentais e não-governamentais. Incluímos aqui os refugiados e os migrantes que, em situação irregular, integram a categoria mundial dos deslocados, incluindo os refugiados por questões ambientais e os apátridas. Outros, mal podem ser identificados em consequência da sua "invisibilidade" por não terem seus perfis definidos por Convenções Internacionais. Mas, da mesma forma, estes cidadãos buscam por ofertas de uma vida melhor, até então corroída pelas defasagens que afetam o desenvolvimento humano.

A imagem recorrente, pensando aqui em um tempo de longa duração, é aquela da população mundial em constante movimento, fugindo das grandes fraturas físicas e simbólicas que provocam situações de desequilíbrio mental, social e político. Os refugiados, nestas últimas décadas, representam as principais vítimas das crises humanitárias que têm abalado o mundo contemporâneo em constante mutação. Neste exato momento, por exemplo, vislumbramos imagens de homens e mulheres afegãs, de todas as idades e classes sociais, forçados a abandonar seu país para defender suas vidas e seus direitos. Estas novas situações migratórias - que, muitas vezes, reproduzem situações históricas vivenciadas principalmente no século XX - nos colocam em estado de alerta diante dos riscos de desintegração familiar e da violação dos direitos humanos.

Tais mudanças implicam, por sua vez, na reformulação das identidades culturais e religiosas, exigindo dos estudiosos dos movimentos populacionais, um constante estado de atenção e de atualização dos seus conhecimentos a respeito 
das migrações. Daí a relevância deste e de outros tantos dossiês acadêmicos preocupados em entender as migrações sob uma perspectiva global, diferenciada dos fluxos anteriores, cujas tendências exigem estudos comparativos e interdisciplinares. A riqueza das discussões teóricas e metodológicas, valorizadas por suas especificidades e pelos lugares das "falas" de cada autor, devem contribuir para a promoção de políticas públicas que, de alguma forma, favoreçam a integração, a inserção social e ocupacional dos (i)migrantes nos países de acolhimento.

Tendo em vista a importância da construção de uma obra coletiva para a produção de novos conhecimentos sobre as modalidades dos deslocamentos humanos, resolvemos organizar este dossiê em torno de segmentos que implicam na valorização das narrativas e nas formas de representação produzidas pelos migrantes. Além de incentivar o debate sobre o tema das migrações, pretendemos também expor parte dos projetos individuais que, de alguma forma, integram a comunidade dos pesquisadores do LEER- Laboratório de Estudos sobre Etnicidade, Racismo e Discriminação, sob a minha coordenação junto ao Departamento de História da Faculdade de Filosofia, Letras e Ciências Humanas da Universidade de São Paulo. Enquanto um projeto coletivo financiado pela Fapesp - Fundação de Amparo à Pesquisa do Estado de São Paulo, o grupo contempla diversos campos do saber.

O diálogo entre as disciplinas, a troca contínua de experiências e a busca por novas formas de análise, permite ultrapassar os limites de determinados marcadores metodológicos e do próprio arcabouço teórico. Assim, além dos pesquisadores do LEER-USP, a revista CESLA abriu espaço também aos estudiosos de outras instituições acadêmicas, com o objetivo de enriquecer as abordagens acerca da identidade e da memória dos (i)migrantes, em constante movimento. Trabalhando com o espaço e a memória simultaneamente - com o objetivo de perceber as simbologias e as representações oferecidas por diferentes formas de narrar o fenômeno das migrações, individuais ou em grupos - pretendemos contribuir para a formulação de uma visão mais humana sobre o uso dos espaços e da figura do imigrante, nem sempre um refugiado.

A compreensão dos objetos de estudos contemplados neste dossiê, tornase, extremamente relevante para a investigação dos deslocamentos humanos históricos e contemporâneos -, tema que por sua complexidade, se beneficia do caráter integrado e articulado do saber. O fenômeno migratório - definido pelas narrativas e representações produzidas pelos (i)migrantes - afirma-se com características múltiplas, longe de serem fluidas, homogêneas ou lineares. Cada artigo distingue-se por seu objeto de estudo (açorianos, italianos, portugueses, nordestinos) 
analisado sob diferentes prismas (sociais, culturais, demográficos, políticos e econômicos), pontuados pela multiplicidade de formas com que se revestem. Ao mesmo tempo, estabelecem dimensões, temporalidades específicas e articulações com o espaço circundante, fatores que impõem novos desafios aos estudiosos. Esta é também uma das formas encontrada pelo LEER-USP e a revista CESLA para atender a urgência de se combater os estereótipos, a violência, a dominação e a segregação, motores da violação dos direitos humanos.

Cada pesquisador que integra este dossiê, procurou expor a abrangência e a intensidade com que os processos de deslocamentos humanos se apresentam, com ênfase nas diferenças entre os indivíduos e os grupos que agem, reagem e interagem aos agentes externos. Sob este viés, o dossiê n. 27 da Revista del CESLA. International Latin American Studies Review - além de aportar novos conhecimentos sobre as questões que envolvem a mobilidade humana - pretende contribuir para o aprofundamento do tema ao abarcar múltiplas tipologias de fontes documentais, lugares e reservas de memória étnica, social e cultural das migrações. Os artigos aqui publicados reúnem universos que permeiam diferentes fronteiras geográficas, culturais, metodológicas e epistemológicas, entrelaçando história, memória, identidade, etnicidade, gênero e cultura. Nesta ordem, serão apresentados os seguintes textos e seus respectivos autores:

- “Uma história difícil de ser contada": A experiência do deslocamento forçado e os dilemas da memória e do esquecimento ("A history hard to be told": The experience of forced displacement and the dilemmas of memory and forgetting), de Roseli Boschilia (Universidade Federal do Paraná, Brasil). Segundo a autora, o seu texto "nos instiga a refletir sobre os dilemas da memória e do esquecimento presentes em relatos de sujeitos históricos que vivenciaram a experiência do deslocamento forçado, recorrendo "às narrativas de Boleslawa Smolinska Kowalczuk, imigrante de origem polonesa, que se radicou no Brasil na segunda metade da década de 1940, cuja trajetória pessoal foi marcada, de modo irreversível, pela experiência do recrutamento compulsório, no contexto da Segunda Guerra Mundial."

- $\quad$ Arte e artistas migrantes: Um universo simbólico na formação da sociedade brasileira (Art and Migrant Artists: A symbolic universe in the formation of Brazilian society), de Mirian Silva Rossi (Pesquisadora LEER-USP e cocoordenadora do projeto Fapesp/LEER). Neste seu texto, Miriam Rossi discorre sobre o constante dilema do "quem somos" e "o que 
somos", tendo como linha de argumentação o lugar que a arte e os artistas imigrantes ocuparam (e ainda ocupam), "ao longo do contraditório processo de formação da sociedade brasileira". A partir da seleção de um corpus privilegiado de fontes iconográficas, Miriam Rossi tem como objetivo transitar "pelo universo simbólico do qual emergem as formas e as representações artísticas, as relações e as significações", partindo do pressuposto de que "a arte promove o encontro do homem consigo mesmo e com a sua cultura".

- $\quad O$ percurso invisível de açorianos no Brasil do século XIX (The Invisible Journey of Azoreans in 19th Century Brazil), de Fabiene Passamani Mariano (do Instituto Federal do Espírito Santo, Brasil). Ao privilegiar como objeto de estudo a Colônia Agrícola de Vianna, na então Capitania do Espírito Santo, na qual foram fixados imigrantes portugueses naturais da Ilhas dos Açores, que ali aportaram a partir de 1813 - a autora faz uma revisão crítica das fontes bibliográficas sobre os açorianos, no contento do Espírito Santo.

- $\quad$ O trabalho e a cidade: Uma análise sobre alguns aspectos laborais e a circulação de criadas estrangeiras na cidade do Rio de Janeiro, 1880-1930 (Work and the City: an analysis of some labor aspects and the circulation of foreign maids in the city of Rio de Janeiro, 1880-1930), de Natália Batista Peçanha (Universidade Federal do Piauí, Brasil). Sob a perspectiva da História do Trabalho, a autora reconstitui as atividades laborais que mais empregavam mulheres, sobretudo de cor, desde os tempos da escravidão, priorizando "a participação das criadas europeias no serviço doméstico carioca, destacando as formas pelas quais se inseriam na dita atividade". Atenta também para as nacionalidades e a circulação dessas personagens na cidade do Rio de Janeiro, valendo-se dos anúncios de jornais publicados em periódicos cariocas, como o Jornal do Commercio.

- Impressões da São Paulo nordestina: entre territórios e identidades no imaginário coletivo (Impressions of São Paulo nordestina: Between territories and identities in the collective imaginary), de Elis Regina Barbosa Angelo (Universidade Federal Rural do Rio de Janeiro, Brasil e pesquisadora do projeto Fapesp/LEER-USP). Em busca de elementos do imaginário social que definem as identidades culturais nordestinas formadas e mantidas fora do Nordeste, Elis Regina desloca o foco dos estudos migratórios para São Paulo, o principal pólo aglutinador de 
migrantes no Brasil. Através da religiosidade e das festividades, reconstitui as imagens simbólicas que, na "cidade da garoa", formam espaços privilegiados de saberes. Em busca dos contornos destes espaços, a autora privilegia "os lugares de memória e os territórios que contemplam essas experiências migrantes", além de elaborar uma revisão bibliográfica sobre a produção de identidades. Uma estratégia sábia de criar facilitadores de justiça e engajamento social.

- A constituição do "eu" em entrevistas com descendentes de italianos no Brasil: tempo e espaço como marcas de memória e identidade (The constitution of the "I" in interviews with Italian descendants in Brazil: Time and space as memory and identity traces), de Elisabetta Santoro e Giliola Maggio, ambas do Departamento de Letras da FFLCH- Universidade de São Paulo, e pesquisadoras do LEER. O texto contempla os resultados dos grupos de pesquisa: "Língua, Identidade e Memória: os italianos dos italianos do Brasil" e do projeto Fapesp/LEER "Deslocamentos Humanos, Narrativas e Representações nos Brasil, Séculos XIX e XX". As autoras partem das narrativas de um grupo de italianos no Brasil, que explicam o significado de ser italiano de origem, mas brasileiros de nascimento, vinculado à memória de seu passado familiar. Além de dar a conhecer vários aspectos das histórias de vida dos descendentes de italianos no Brasil, oferecem também um modelo teórico e metodológico da aplicação da técnica da História Oral aos estudos sobre os deslocamentos humanos. 